\title{
Response to: Comment on "Are Patients with Polycystic Ovarian Syndrome Ideal Candidates for Oocyte Donation?”
}

\author{
George Queiroz Vaz, ${ }^{1,2}$ Alessandra Viviane Evangelista, \\ Cassio Alessandro Paganoti Sartorio, ${ }^{2}$ \\ Maria Cecilia Almeida Cardoso, ${ }^{2}$ Maria Cecilia Erthal, ${ }^{2}$ \\ Paulo Gallo, ${ }^{1,2}$ and Marco Aurelio Pinho Oliveira ${ }^{1}$ \\ ${ }^{1}$ Department of Gynecology, Rio de Janeiro State University, 20551-030 Rio de Janeiro, RJ, Brazil \\ ${ }^{2}$ Vida Fertility Center, 22793-080 Rio de Janeiro, RJ, Brazil \\ Correspondence should be addressed to George Queiroz Vaz; georgequeirozvaz@gmail.com
}

Received 2 May 2017; Accepted 10 July 2017; Published 18 September 2017

Academic Editor: Hartmut Jaeschke

Copyright (c) 2017 George Queiroz Vaz et al. This is an open access article distributed under the Creative Commons Attribution License, which permits unrestricted use, distribution, and reproduction in any medium, provided the original work is properly cited.

Chetan and Dada commented on our study [1] titled "Are Patients with Polycystic Ovarian Syndrome Ideal Candidates for Oocyte Donation?" that analyzed the impact of PCOS in oocytes donation treatments [2].

The role of donated oocytes in the treatment of infertile women, especially in advanced age, is well established.

However, there are different practices for obtaining donated oocytes [3]. It is worth noting that in Brazil, due to local law, only oocytes from patients who are undergoing in vitro fertilization and who decide to donate them altruistically can be used [4]. In addition to concerns regarding the age of the donor, we should note the infertility that led the donor to have the indication of IVF and consider whether this will influence the outcome of the pregnancy in the recipient.

Chetan and Dada drew attention to the importance of male factors in the success of implantation and in the clinical pregnancy rate [1], especially the paternal effect of sperm DNA damage in the stages of embryonic development, and also criticized the fact that the male factors have not been studied in this study. Obviously, we agree on the importance of male factors in IVF success rates. The objective of our study was to know if there would be any impact on the IVF results of recipient patients with donor oocytes from infertile women with a diagnosis of PCOS compared to donors with no PCOS. In our study, there is no reason to believe that male factors would be unbalanced between those two groups of recipients. Male factors probably influenced negatively the results of both groups of recipients.

At the end of their letter to the editor, Chetan and Dada looked at the altered hormonal environment in women with PCOS. They raised a concern that it could affect the oocyte epigenome, in addition to these oocytes negatively affecting fertilization, implantation, and pregnancy rates. We had the same concerns, which motivated us to delineate this clinical study.

A meta-analysis by Heijnen et al. includes nine studies comparing reproductive outcomes of IVF in patients with PCOS and no PCOS [5]. They did not find any difference in pregnancy rates between the groups. Similarly, in our study, we did not find differences in clinical pregnancy rates in oocyte recipients patients with PCOS compared to non-PCOS patients. We understand Chetan and Dada's claim that oocytes from patients with PCOS should be used with caution, but it seems from our results that patients with polycystic ovary syndrome should not be discarded for oocyte donation programs [2]. 


\section{Conflicts of Interest}

The authors declare that there are no conflicts of interest regarding the publication of this manuscript.

\section{References}

[1] S. Chetan and R. Dada, "Comment on "Are patients with polycystic ovarian syndrome ideal candidates for oocyte donation?"," BioMed Research International, vol. 2017, pp. 1-2, 2017.

[2] G. Q. Vaz, A. V. Evangelista, C. A. P. Sartorio et al., "Are patients with polycystic ovarian syndrome ideal candidates for oocyte donation?" BioMed Research International, vol. 2016, Article ID 5701609, 2016.

[3] M. Faddy, R. Gosden, K. Ahuja, and K. Elder, "Egg sharing for assisted conception: a window on oocyte quality," Reproductive BioMedicine Online, vol. 22, no. 1, pp. 88-93, 2011.

[4] S. Purewal and O. B. A. van den Akker, "Systematic review of oocyte donation: investigating attitudes, motivations and experiences," Human Reproduction Update, vol. 15, no. 5, pp. 499-515, 2009.

[5] E. M. E. W. Heijnen, M. J. C. Eijkemans, E. G. Hughes, J. S. E. Laven, N. S. Macklon, and B. C. J. M. Fauser, "A meta-analysis of outcomes of conventional IVF in women with polycystic ovary syndrome," Human Reproduction Update, vol. 12, no. 1, pp. 1321, 2006. 


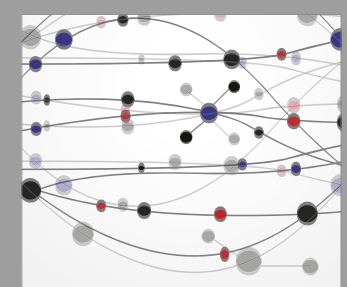

The Scientific World Journal
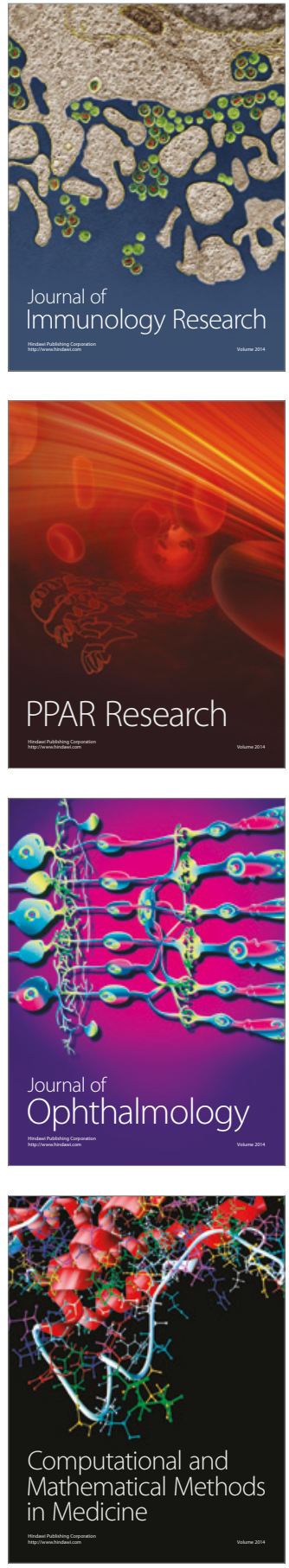

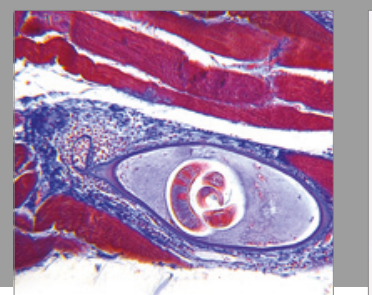

Gastroenterology Research and Practice
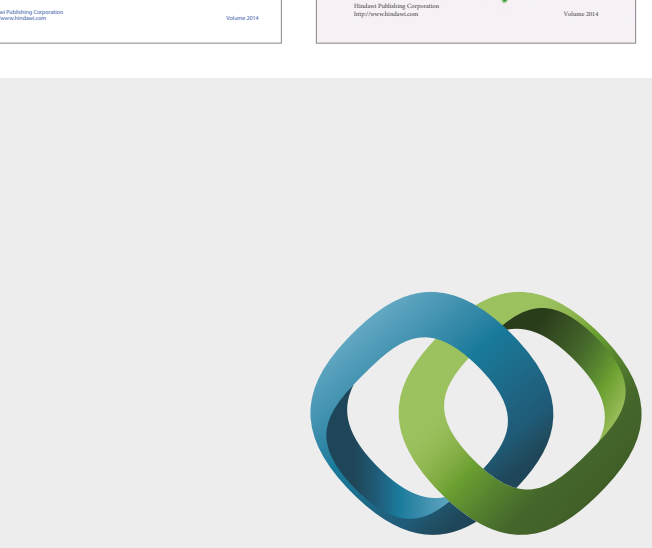

\section{Hindawi}

Submit your manuscripts at

https://www.hindawi.com
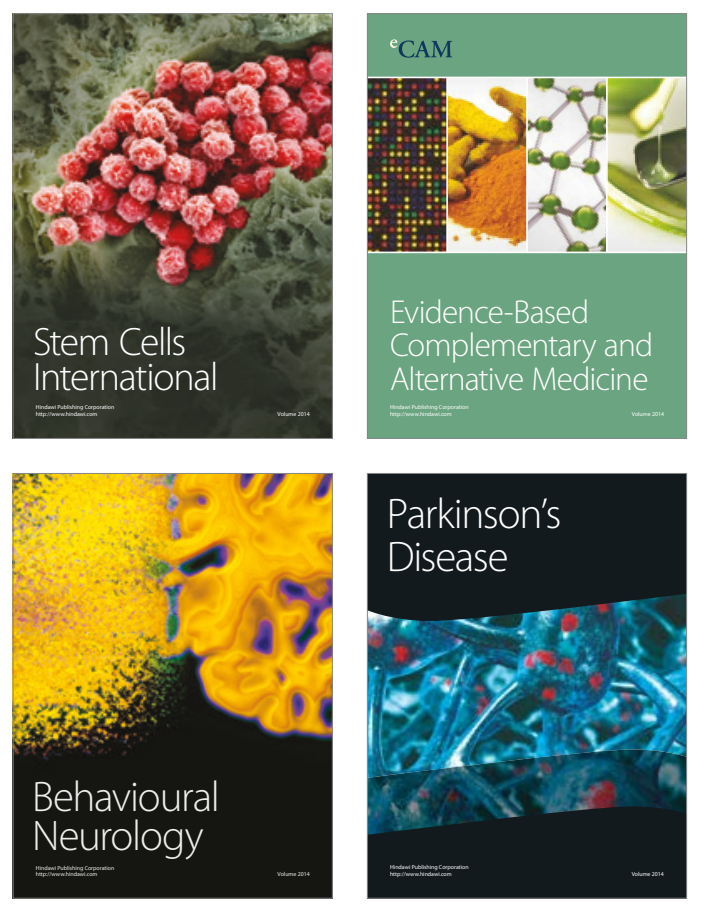
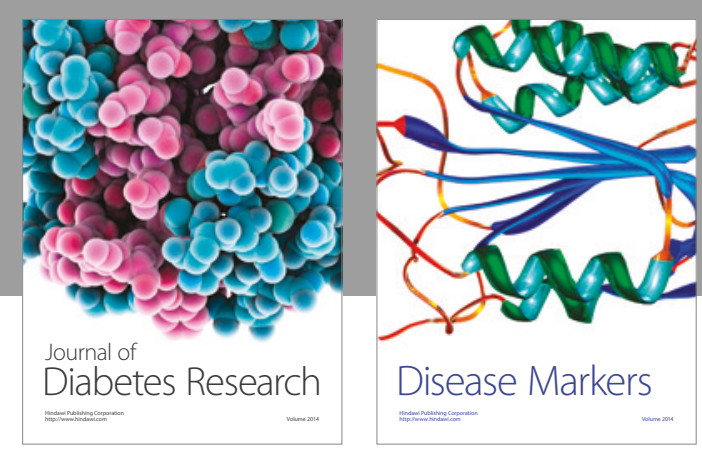

Disease Markers
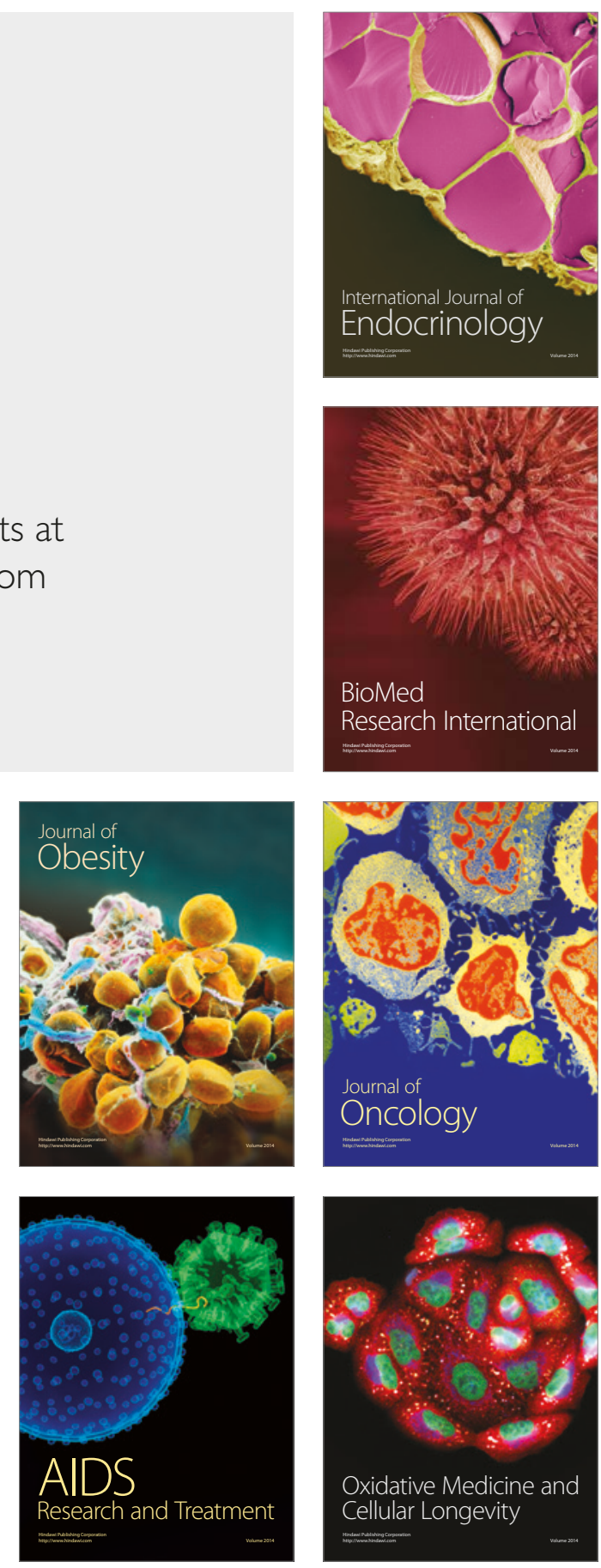